\title{
AÇÕES DE SENSIBILIZAÇÃO NO PROCESSO DE AUTO-AVALIAÇÃO EM INSTITUIÇÕES QUE ATUAM NA MODALIDADE EADCOORDENADO PELA COMISSÃO PRÓPRIA DE AVALIAÇÃO (CPA)
}

\author{
CURITIBA/PR MAIO/2018
}

\author{
Valdilson Aparecido Lopes - Uninter - valdilson.l@uninter.com \\ Tânia Aparecida Soares - Uninter - tania.so@uninter.com \\ SIDERLY DO CARMO DAHLE DE ALMEIDA －Uninter - siderly.c@gmail.com
}

Tipo: Investigação Científica (IC)

Natureza: Planejamento de Pesquisa

Categoria: Estratégias e Políticas

Setor Educacional: EDUCAÇÃO SUPERIOR

\begin{abstract}
RESUMO
A Comissão Própria de Avaliação (CPA) é condicionada pela implantação do Sistema de Avaliação do Ensino Superior - SINAES, do INEP-MEC (Lei 10.861, de 14 de abril de 2004) e seu objetivo é supervisionar, apoiar e coordenar diferentes etapas da autoavaliação institucional. Ela possui membros de diferentes segmentos da comunidade acadêmica que oferecem subsídios à efetivação de um amplo e contínuo processo de aperfeiçoamento institucional. Suas ações são voltadas à autoavaliação interna, aplicadas, divulgadas e analisadas pela CPA. As avaliações envolvam todos os aspectos do processo de ensino aprendizagem, bem como, atividades de extensão e pesquisa, o conjunto das condições físicas e administrativas, dos cursos nas modalidades presencial e a distância. Contemplando ainda, os aspectos relacionados à gestão institucional, detalhados nas diferentes dimensões do SINAES. Dessa forma, a CPA realiza o acompanhamento dos resultados das ações de todas as áreas, para a mudança ou manutenção de práticas e posturas profissionais. O processo de desenvolvimento da CPA ao longo dos anos revela um permanente comprometimento tendo na avaliação institucional uma de suas prioridades em suas ações de sensibilização no instrumento de autoavaliação na modalidade EAD, visto ser ela um instrumento afetivo e essencial para nortear as políticas de ensino.
\end{abstract}

Palavras-chave: INEP e EAD; Instrumento, Sensibilização e Autoavaliação na EAD; CPA na EAD 


\section{INTRODUÇÃo}

Esta pesquisa desenvolveu-se a partir da observação dos autores sobre a questão da autoavaliação institucional em instituições de ensino superior que trabalham com a modalidade EAD, tendo por tema: As ações de sensibilização em cursos superiores na modalidade EAD e a promoção do envolvimento da comunidade acadêmica no processo de autoavaliação coordenado pela Comissão Própria de Avaliação (CPA).

Neste contexto, a pergunta que se buscou responder com o estudo foi: "Como as ações de sensibilização nos cursos ofertados pelas Instituições de Ensino Superior (IES) na modalidade EAD podem prover o envolvimento da comunidade acadêmica no processo de autoavaliação coordenado pela Comissão Própria de Avaliação (CPA) de forma a contribuir na qualidade de oferta destes cursos? "Considerando o problema acima exposto, este artigo teve por objetivo analisar como as ações de sensibilização propostas pela Comissão Própria de Avaliação (CPA) podem promover o envolvimento da comunidade acadêmica no processo de autoavaliação de forma a contribuir com a qualidade dos cursos oferecidos.

Este trabalho justifica-se pois o Ministério da Educação e Cultura (MEC) por meio da Lei Federal no 10.861, de 14 de abril de 2004 institucionalizou a Comissão Nacional de Avaliação da Educação Superior (CONAES), como um órgão colegiado de coordenação, supervisão e regulamentação do Sistema Nacional de Avaliação da Educação Superior (SINAES), que preconiza que toda Instituição de Ensino Superior (IES), pública ou privada nas modalidades presencias e a distância, deve constituir uma Comissão Própria de Avaliação (CPA), com responsabilidade do processo de autoavaliação considerando na elaboração de um instrumento, cinco eixos: Planejamento e Avaliação Institucional; Desenvolvimento Institucional; Políticas Acadêmicas; Políticas de Gestão e Infraestrutura.

O processo de autoavaliação é um processo de indução da qualidade institucional, que em consonância com o Plano de Desenvolvimento Institucional (PDI) - previsto para um quinquênio -, passa a ser compreendido como um processo de autoconhecimento conduzido pela Comissão Própria de Avaliação (CPA) que tem a responsabilidade de envolver toda comunidade acadêmica e civil neste processo, transformando os resultados em conhecimento e possibilitando a melhoria das ações a serem implementadas pela Instituição de Ensino Superior (IES) posteriormente.

Como justificativa prática, esta pesquisa se faz necessária, face ao envolvimento dos pesquisadores nos processos de autoavaliação das Instituições de Ensino Superior 
(IES) na modalidade EAD - considerando a sensibilização a ações planejadas e as metodologias adotadas, de modo a facilitar a articulação entre os participantes e a observância aos prazos para a entrega dos relatórios.

\section{AUTOAVALIAÇÃO INSTITUCIONAL E LEGISLAÇÃO}

A avaliação institucional interna (autoavaliação) está inserida no contexto do Sistema Nacional de Avaliação da Educação Superior (SINAES) que, instituído pela Lei № 10.861 de 14 de abril de 2004, tem entre suas finalidades a melhoria da qualidade da educação superior e a expansão da sua oferta. Conforme disposto no inciso VIII do Art. $3^{\circ}$, da Lei do SINAES o,

planejamento e avaliação, especialmente os processos, resultados e eficácia da autoavaliação institucional devem ser considerados nas ações de avaliação e de desenvolvimento institucional. Ainda, no Art. $3^{\circ}$, $§ 20$, define-se que para a avaliação das instituições, serão utilizados procedimentos e instrumentos diversificados, dentre os quais a auto-avaliação e a avaliação externa in loco. (BRASIL, 2004)

De modo a se compreender o papel da autoavaliação institucional, faz-se importante conceituar alguns outros documentos. O Plano de Desenvolvimento Institucional (PDI) das Instituições de Ensino Superior (IES), em consonância com o processo de autoavaliação conduzido pela Comissão Própria de Avaliação (CPA), deve ser entendido como um processo de autoconhecimento que envolve todos os atores que atuam na instituição, a fim de analisar as atividades acadêmicas desenvolvidas.

Este processo de autoavaliação apresenta-se como um processo de excelência da qualidade das IES, que se vale dos resultados das avaliações externas e as informações coletadas e organizadas a partir do Plano de Desenvolvimento Institucional (PDI), transformando-os em conhecimento e possibilitando sua apropriação pelos atores envolvidos. Afinal, as ações de melhoria a serem implementadas pela instituição dependem de sua própria compreensão, de seu autoconhecimento.

O processo de autoavaliação das Instituições de Ensino Superior (IES) deverá ser consolidado por meio do relatório de autoavaliação institucional, com a finalidade fomentar a cultura de avaliação institucional e subsidiar os processos de avaliação externa. A Diretoria de Avaliação da Educação Superior (DAES), do Instituto Nacional de Estudos e Pesquisas Educacionais Anísio Teixeira (INEP), autarquia do Ministério da Educação (MEC), com a orientação da Comissão Nacional de Avaliação da Educação Superior (CONAES), de forma a colaborar com Instituições de Ensino Superior (IES), 
estabelece um roteiro para a elaboração do Relatório de Autoavaliação Institucional.

O relatório de autoavaliação institucional, elaborado pelos membros da Comissão Própria de Avaliação (CPA), deve atender a seguinte estruturação: introdução, metodologia, desenvolvimento, análise dos dados e das informações e ações previstas com base nessa análise.

$\mathrm{Na}$ introdução deverá conter os dados da Faculdade/Centro Universitário/ Universidade, a composição da CPA e o planejamento estratégico de autoavaliação deverão ser informados neste campo, bem como o ano a que se refere, relatando se o relatório é parcial ou integral, conforme esta nota técnica. Enquanto que na metodologia, os instrumentos que serão utilizados deverão ser descritos de forma a atender os segmentos da comunidade acadêmica e da sociedade civil consultados e as técnicas utilizadas para análise dos dados.

No decorrer do desenvolvimento, deverão ser apresentados os dados e as informações pertinentes a cada eixo/dimensão, de acordo com o Plano de Desenvolvimento Institucional (PDI) e a identidade da Instituição de Ensino Superior (IES). A seção do relatório destinada ao desenvolvimento deverá ser organizada em cinco tópicos, correspondentes aos cinco eixos que contemplam as dez dimensões dispostas no art. $3^{\circ}$ da Lei $N^{\circ} 10.861$, que institui o Sistema Nacional de Avaliação da Educação Superior (SINAES) são: EIXO 1: PLANEJAMENTO E AVALIAÇÃO INSTITUCIONAL: Dimensão 8: Planejamento e Avaliação; EIXO 2: DESENVOLVIMENTO INSTITUCIONAL: Dimensão 1: Missão e Plano de Desenvolvimento Institucional e Dimensão 3: Responsabilidade Social da Instituição; EIXO 3: POLÍTICAS ACADÊMICAS: Dimensão 2: Políticas para o Ensino, a Pesquisa e a Extensão, Dimensão 4: Comunicação com a Sociedade e Dimensão 9: Política de Atendimento aos Discentes; EIXO 4: POLÍTICAS DE GESTÃO: Dimensão 5: Políticas de Pessoal, Dimensão 6: Organização e Gestão da Instituição e Dimensão 10: Sustentabilidade Financeira; EIXO 5: INFRAESTRUTURA FísICA: Dimensão 7: Infraestrutura Física (BRASIL, 2014)

No que se refere a análise dos dados e das informações, os dados e as informações apresentadas no desenvolvimento deverão ser analisados e apropriados pelos atores da instituição, culminando no planejamento e na execução das ações. Nesta seção deverá ser realizado um diagnóstico a respeito da IES, ressaltando os avanços e os desafios a serem enfrentados. Também deverá ser evidenciado no relatório o quanto foi alcançado em relação ao que foi estabelecido no Plano de Desenvolvimento Institucional (PDI), considerando o perfil e a identidade da IES. 
Por outro lado, as ações com base na análise, deverão ser previstas a partir da análise dos dados e das informações, visando à melhoria das atividades acadêmicas e de gestão da instituição. Assim, tonar-se-á viável estabelecer continuidade devido a coerência entre os dados apresentados, facilitando o desenvolvimento do relatório de autoavaliação (versão parcial e integral), bem como o processo avaliativo em sua integralidade. O relatório parcial deverá contemplar as ações e informações indicadas pela Comissão Própria de Avaliação (CPA) no ano de referência (anterior), explicitando os 5 eixos e 10 dimensões trabalhadas.

É relevante haver coerência entre o planejamento e a avaliação externa e a avaliação interna (autoavaliação) no sentido de auxiliar a instituição a identificar suas potencialidades e fragilidades, carências e necessidades, a definir suas prioridades, contribuindo para a sua evolução a partir dos processos de planejamento e avaliação institucional como instrumento de gestão e de ações acadêmicas e administrativas de melhoria institucional junto à comunidade acadêmica e à sociedade. (NUNES; DUARTE; PEREIRA, 2017, p. 377)

O relatório integral deverá indicar as ações e informações levantadas pela CPA no ano de referência (anterior), assim como, deverá discutir o conteúdo relacionado aos dois relatórios (parciais anteriores), descrevendo em uma análise global a relação entre o Plano de Desenvolvimento Institucional (PDI) com os 5 eixos e as 10 dimensões do instrumento, de acordo com as atividades acadêmicas e de gestão. Deverá, ainda, apresentar um plano de ações de melhoria à IES.

No que se refere a periodicidade da entrega do relatório de autoavaliação, ficou fixado que a partir do ano de referência de 2015 o relatório de autoavaliação seria submetido anualmente, para análise por meio do Sistema e-MEC, ao longo de um período de três anos. Sendo que nos 2 primeiros anos, o relatório deveria ser submetido em sua versão parcial e no terceiro ano, submetido em sua versão integral.

\section{O INSTRUMENTO DE AVALIAÇÃO DO SINAES}

A Comissão Própria de Avaliação (CPA), responsável pela elaboração do instrumento de avaliação (questionário) a-como uma importante ferramenta -, possibilita a coleta de informações junto ao corpo docente, corpo discente e corpo técnico administrativo da Instituições de Ensino Superior (IES). O instrumento de avaliação institucional, permite o apontamento de áreas e setores com fragilidades, que requerem melhorias.

O Sistema Nacional de Avaliação da Educação Superior (SINAES) é, pois, regido pelos 
princípios de que a educação superior constituiu direito social e dever do Estado, e a formação e a produção do conhecimento é relevante para o desenvolvimento conjunto da população e para o avanço da ciência. Os demais princípios dizem respeito ao fortalecimento dos valores éticos, visando melhorar compromissos institucionais, a dinâmica dos processos e das relações, o respeito à identidade e à diversidade institucional, a globalidade expressa na integração dos instrumentos de regulação e de avaliação em uso pelo Estado e nas IES, a busca de legitimidade técnica e de legitimidade ética e política. (WEBER, 2010, p. 1259)

Conforme disposto no $\S$ VIII do Art. 3ำ, da Lei do SINAES, o "planejamento e avaliação, especialmente os processos, resultados e eficácia da autoavaliação institucional" (BRASIL, 2014) devem ser considerados nas ações de avaliação e de desenvolvimento institucional. Ainda no Art. $3^{\circ}, \S 20$, define-se que "para a avaliação das instituições, serão utilizados procedimentos e instrumentos diversificados, dentre os quais a autoavaliação e a avaliação externa in loco". (BRASIL, 2014).

No processo de avaliação institucional, os dados são coletados por meio de um instrumento que possibilitaráaos membros da Comissão Própria de Avaliação (CPA), mensurar as fragilidades/potencialidades da IES dentro de 5 eixos e 10 dimensões, bem como, permitea análise de impressões obtidas pela Comissão Própria de Avaliação (CPA) decorrente da metodologia utilizada no processo avaliativo cujos resultados estarão impressos em relatórios.

Essa etapa do processo caracteriza-se pela definição de uma metodologia adequada para a obtenção das informações necessárias, visando responder às questões do instrumento. De forma a buscar a exatidão dos resultados, pode se optar por um instrumento com questões fechadas, disponibilizado em versões específicas para os segmentos: discente, docente e técnico-administrativo.

Os membros da Comissão Própria de Avaliação (CPA) são responsáveis pela execução do processo entre sensibilização, elaboração do instrumento, aplicação do instrumento, tratamento das informações obtidas até a escrita do relatório e devolutiva à comunidade institucional. Contudo, faz-se necessário que seja atendido o cumprimento de 05 eixos e de 10 dimensões no contexto do Sistema Nacional de Avaliação da Educação Superior (SINAES), instituído pela Lei no 10.861 de 14 de abril de 2004.

\section{AÇÕES DE SENSIBILIZAÇÃo NO PROCESSO DE AUtOAVALIAÇÃo NA MODALIDADE EAD}


A Comissão Própria de Avaliação (CPA) tem por objetivo promover a melhoria da qualidade da educação superior realizada no processo de avaliação das Instituições de Ensino (IES) como instrumento norteador das ações e transformações necessárias ao pleno desenvolvimento da Instituição. Os objetivos poderão ser verificados no o regulamento da Comissão Própria de Avaliação (CPA) que apresenta as etapas necessárias para que ocorra o processo de sensibilização sendo que se faz necessário inicial mente estabelecer algumas etapas que poderão ser verificadas na figura 1:

Figura 1 - Etapas de preparação

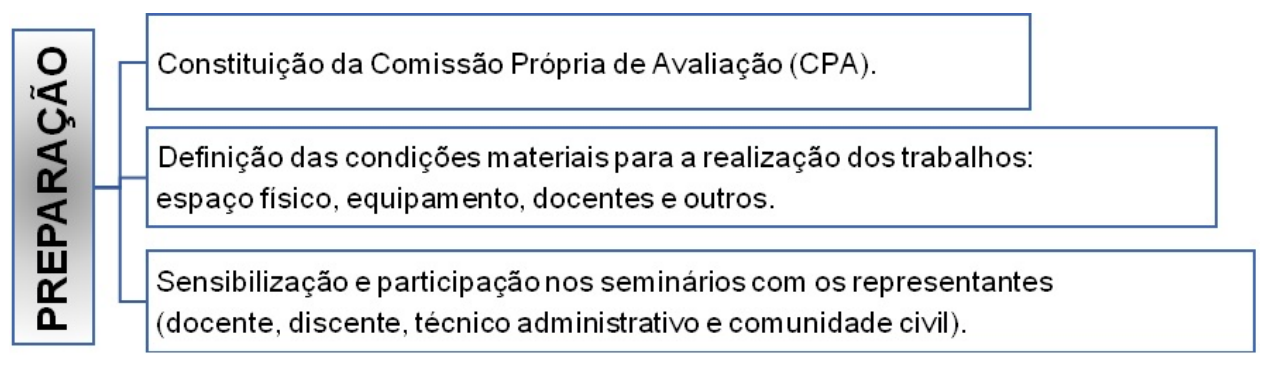

Fonte: Os autores fundamentos em INEP (2014)

O processo de sensibilização tem início na proposta metodológica de trabalho em quese planejam, desenvolvem e consolidam as informações obtidas junto à comunidade institucional no momento da autoavaliação. No momento do planejamento, os membros da Comissão Própria de Avaliação (CPA), possibilitam um debate e um feedback de sua metodologia de trabalho entre seus membros para a reorganização e estruturação do instrumento de autoavaliação.

Na semana de sensibilização, a coordenação da Comissão Própria de Avaliação (CPA), procura estimular e conscientizar para a importância das respostas à cada questão do instrumento utilizado no processo de autoavaliação institucional e se vale de banners, cartazes, filipetas no site institucional, Ambiente Virtual de Aprendizagem (AVA), redes sociais, vídeo aula, fórum, chat, tira dúvidas (Live), Sensibilização (via satélite) dentre outros recursos. As informações disponibilizadas para a Comissão Própria de Avaliação (CPA) são coletadas a partir do instrumento de avaliação elaborado pelos membros da comissão com metodologia de preenchimento voluntário do instrumento pela comunidade constitucional (docente, discente, técnico-administrativo e comunidade civil).

Já na fase do desenvolvimento, os membros da Comissão Própria de Avaliação (CPA), tem a missão de implementar o instrumento, observando o Calendário Institucional e o 
Calendário específico proposto pelos membros da Comissão Própria de Avaliação (CPA) sem perder de vista a coleta de informações, fontes fundamentais para o andamento e conclusão do trabalho de autoavaliação institucional.

Figura 2 - Etapa de Desenvolvimento

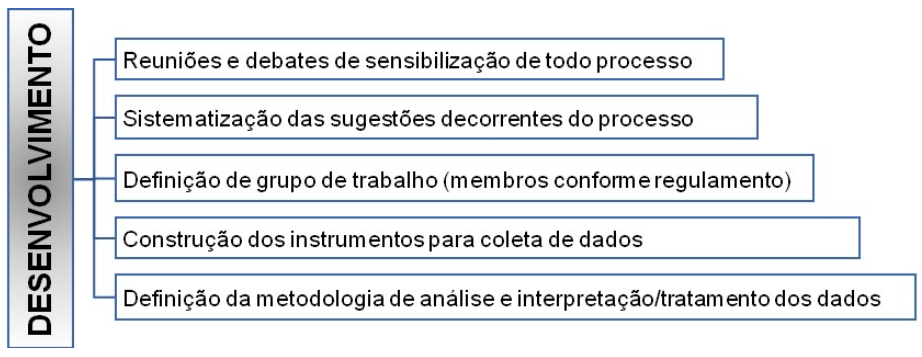

Fonte: Os autores fundamentos em INEP (2014)

Todavia o período de consolidação - fase fundamental para a estruturação do relatório de autoavaliação institucional, o coordenador da Comissão Própria de Avaliação (CPA) descreve a versão inicial do relatório e indica a metodologia de trabalho. $O$ instrumento utilizado (5 eixos e 10 dimensões para a coleta das informações/dados) apresenta em sua estrutura técnicas utilizadas no tratamento e análise dos dados.

Figura 3 - Etapa de consolidação

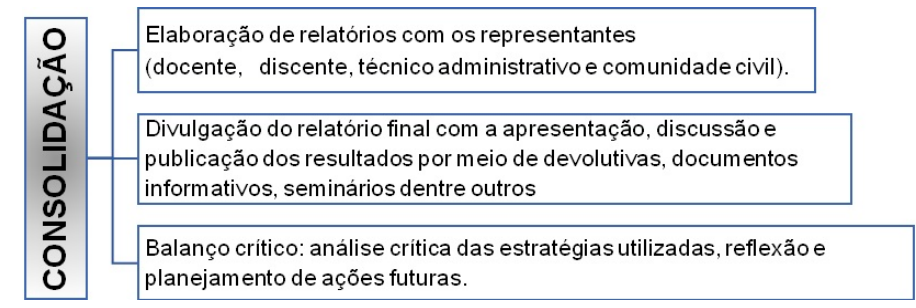

Fonte: Os autores fundamentos em INEP (2014)

No período de consolidação, a Comissão Própria de Avaliação (CPA), sistematiza as informações que posteriormente serão apresentadas ao Núcleo Docente Estruturante (NDE), colegiado de curso e Conselho Superior (CONSU) e demais membros as IES. Estas informações referentes aos 5 eixos e 10 dimensões, fortalece as discussões para o recredenciamento da Instituição de Ensino Superior (IES), reconhecimento de cursos superiores, renovação de reconhecimento e autorização de funcionamentos de futuros cursos.

A Coordenação da Comissão Própria de Avaliação (CPA), na fase de sensibilização - 
conforme previsto no calendário institucional e calendário específico da CPA, possibilita no primeiro dia de sensibilização uma devolutiva do resultado correspondente aos 5 eixos e as 10 dimensões avaliadas, possibilitando um feedback para a comunidade institucional.

Após a coleta dos dados no processo de autoavaliação, a coordenação da Comissão Própria de Avaliação (CPA) juntamente com seus membros, no período de sensibilização realizada com a comunidade institucional da Faculdade/Centro Universitário/Universidade, reúne o corpo docente, corpo discente, corpo técnicoadministrativo e representante da comunidade civil com o objetivo de apresentar cada eixo/dimensão tabulados mediante dados obtidos no processo de autoavaliação institucional bem como o instrumento de autoavaliação.

\section{CONSIDERAÇÕES FINAIS}

Como resultado da pesquisa bibliográfica desenvolvida, foi possível perceber que os processos de autoavaliação das Instituições de Ensino Superior (IES) englobam aspectos tais como: desempenho dos alunos nas avaliações regulares, acompanhamento da evasão do curso, desempenho dos alunos no ENADE, resultados das avaliações externas, resultados das avaliações realizadas pela comissão própria de avaliação (CPA) e sustentabilidade econômico financeira.

Contudo, faz-se importante esclarecer, também, que ao mencionar que, com base nas "orientações gerais para o roteiro de autoavaliação das Instituições de Ensino Superior (IES)", elaborado pelo Instituto Nacional de Estudos e Pesquisas Educacionais Anísio Teixeira (INEP), o trabalho da Comissão Própria de Avaliação (CPA), conforme orientações da Lei no 10.861, de 14 de abril de 2004, atende os indicadores relevantes para a instituição em cada um dos 5 eixos e das dez dimensões propostas (agregando os instrumentos de pesquisa que também dessem conta das especificidades da IES e ainda, da delimitação de públicos-alvo específicos: corpo docente, corpo discente e pessoal técnico-administrativo de diferentes setores da IES.

Deste modo, apresentaram-se algumas sugestões de como é possível realizar uma autoavaliação que contemple a coerência entre o plano realizado e o resultado da avaliação obtido, contribuindo para que se possa, em instituições que atuam na modalidade EAD, auxiliar na identificação de potencialidades e fragilidades, estabelecendo-se prioridades e levando, por meio do planejamento, desenvolvimento e consolidação da autoavaliação, a otimização de aspectos acadêmicos e administrativos oferecidos para a comunidade. 


\section{REFERENCIAS}

BRASIL. Lei n. 9.394, de 20 de dezembro de 1996. Estabelece as diretrizes e bases da educação nacional. Brasília, DF: Congresso Nacional, 1996. Disp. em: $<$ http://www.planalto.gov.br/ccivil_03/leis/19394.htm>. Acesso em: 2 fev. 2018.

BRASIL. Decreto $\mathbf{n}^{\circ}$ 5.773, de 09 de maio de 2006. Dispõe sobre o exercício das funções de regulação, supervisão e avaliação de instituições de educação superior e cursos superiores de graduação e sequenciais no sistema federal de ensino. Disp. em http://www2.mec.gov.br/sapiens/portarias/dec5773.htm Acesso 10 abr. 2018.

BRASIL. Lei no 10.861, de 14 de abril de 2004. Institui o Sinaes e dá outras providências. DOU, Brasília, n. 72, 15 abr., Seção I, p. 3-4, 2004.

BRASIL. Portaria n. 92, de 31 de janeiro de 2014. Aprova em extrato os indicadores do Instrumento de Avaliação Institucional Externa para os atos de credenciamento, recredenciamento e transformação de organização acadêmica, modalidade presencialSinaes. DOU, Brasília, 4 fev., n. 2, Seção 1, p. 6-8, 2014.

INSTITUTO NACIONAL DE ESTUDOS E PESQUISAS EDUCACIONAIS ANÍSIO TEIXEIRA (INEP). Nota Técnica INEP/DAES/CONAESno 14 /2014 - Brasília, 09 de outubro de 2014. Roteiro para Relatório de Autoavaliação Institucional.

INSTITUTO NACIONAL DE ENSINO E PESQUISA (INEP). Nota Técnica INEP/DAES/CONAES № 65/2014, Brasília, 09 de outubro de 2014. Roteiro para Relatório de Autoavaliação Institucional.

NUNES, E. B. L. de L. P.; DUARTE, M. M. S. L. T.; PEREIRA, I. C. A. Planejamento e avaliação institucional: um indicador do instrumento de avaliação do SINAES. Avaliação (Campinas), Sorocaba, v. 22, n. 2, p. 373-384, Ago. 2017.

WEBER, Silke. Avaliação e regulação da educação superior: conquistas e impasses.Educ. Soc., Campinas, v. 31, n. 113, p. 1247-1269, dez. 2010. 